Research Article

\title{
Cemented Backfilling Mining Technology for Gently Inclined Coal Seams Using a Continuous Mining and Continuous Backfilling Method
}

\author{
Bin Lu, ${ }^{1}$ Yongliang Li $\mathbb{D},{ }^{2}$ Shizheng Fang, ${ }^{3}$ Hai Lin, ${ }^{3}$ and Ye Zhu ${ }^{1}$ \\ ${ }^{1}$ School of Mechanics and Civil Engineering, China University of Mining \& Technology (Beijing), Beijing 100083, China \\ ${ }^{2}$ School of Energy and Mining Engineering, China University of Mining \& Technology (Beijing), Beijing 100083, China \\ ${ }^{3}$ School of Civil and Resource Engineering, University of Science and Technology Beijing, Beijing 100083, China
}

Correspondence should be addressed to Yongliang Li; lyl_cumtb@163.com

Received 17 December 2020; Revised 6 January 2021; Accepted 16 January 2021; Published 15 February 2021

Academic Editor: Guangchao Zhang

Copyright $(2021$ Bin Lu et al. This is an open access article distributed under the Creative Commons Attribution License, which permits unrestricted use, distribution, and reproduction in any medium, provided the original work is properly cited.

To improve the efficiency and reduce costs of cemented-fill mining, we propose a continuous mining and continuous backfilling (CMCB) method based on the coal resources at the Yuxing mine in Inner Mongolia, China, and constructed a complete filling material transportation system. The new technology is suitable for cemented-fill mining of gently inclined coal seams. Numerical simulations were performed to investigate the dynamic migration law of surrounding rock stress using CMCB cemented-fill mining technology, and similar simulations were conducted to analyze the movement characteristics of the coal overburden. The results show that the coal pillars and filling body alternately bear and support each other during the CMCB process, which resolves the contradiction between mining and filling, achieves parallel mining and filling operations, and improves mining efficiency. The new mining mode exerts minimal disturbance to the overlying rock and effectively controls surface deformation. The engineering application of this technique is promising and provides theoretical guidance and technical support for safe and efficient mining of the same type of coal resources.

\section{Introduction}

The ongoing exhaustion of coal resources in central and eastern China has led mining operations to gradually shift to western China $[1,2]$. However, this region is located within a more fragile ecological environment with limited ecological self-repair capacity and is highly sensitive to mining disturbances. For example, groundwater systems can be easily damaged using traditional mining methods and large cracks and collapse pits can emerge on the ground surface, which can damage surface buildings [3-8].

Backfill mining is an important green mining technology (GMT) method and an effective technical approach to resolve these issues $[9,10]$. Solid backfilling, paste backfilling, and high-water material backfilling techniques have made considerable progress in Chinese coal mines [11-14]. Zhang [15-20] optimized a solid compact-filling mining technology system based on gangue, studied the gangue compaction characteristics, developed efficient backfill mining technology, and identified the mechanism of solid-backfilled overlying strata movement. Zhou [21,22] studied the mechanical properties of paste backfilling materials and proposed further development directions for coal mining technology using paste filling. Zhao [23] used loess to replace fly ash in traditional paste-filling materials and studied the mechanical properties of paste-filling materials using different proportions, which provides a reference for backfill mining in the ecologically fragile areas of western China. Ma $[24,25]$ studied the backfill method for filling nearly horizontal coal seams with high-water materials using the Wongawilli mining method, analyzed the evolution characteristics of overlying strata fractures, and achieved a waterpreserving approach to mining coal resources. Sun and Feng [26-30] analyzed the structure of high-water materials, 
developed ultrahigh-water material (97 vol\%), and studied the control principle of overlying rock movement.

The achievements mentioned above have obtained promising effects in some mining areas and further promoted the development of coal mining technology in China. The control effect of cemented filling mining on surface subsidence is more significant than other filling mining methods [31, 32]. However, traditional longwall cemented backfill mining continues to face the following shortcomings. (1) The initial investment required for backfilling equipment and systems is large and the filling material cost is high. (2) The contradiction between mining and backfilling is prominent. Because backfill materials require a certain curing time, mining and filling cannot be simultaneously operated to their respective maximum extents. This makes it difficult to ensure effective backfill space and time and the efficiency of backfill mining is not particularly high. To address these problems, we developed a full negative-pressure continuous mining method to replace the previous "under-three-objects" approach to coal seams (i.e., under buildings, roads, and water bodies). Extensive scientific and technological research has led to continuous improvement of the technology and equipment system as a new continuous mining and continuous backfilling (CMCB) cemented-filling technique. This technology has been applied in several mining areas, including the Yuxing and Haoyuan mines in Inner Mongolia, and has achieved good results. This paper focuses on the application of CMCB technology for gently inclined coal seams based on the Yuxing mine. The principles of the step-by-step replacement technology are provided as theoretical guidance for coal backfill mining under similar conditions.

\section{Study Location}

The Yuxing coal mine is located in Qipanjing town, Ordos, Inner Mongolia, as shown in Figure 1. The design production capacity is $0.6 \mathrm{Mt} / \mathrm{a}$ and focuses mainly on mine nos. 9 and 16. The buried depth of the no. 9 coal seam is $300-400 \mathrm{~m}$ and the coal seam inclination is $12^{\circ}$. The average thickness of the coal seam is $5 \mathrm{~m}$, which is a typical gently inclined seam. The direct top of the coal seam is fine-grained sandstone with a thickness of $1.69 \mathrm{~m}$, the basic top is medium-grained sandstone with a thickness of $4.86 \mathrm{~m}$, the direct bottom is $0.5 \mathrm{~m}$ thick siltstone, and the basic bottom is fine-grained sandstone with a thickness of $1.24 \mathrm{~m}$. The overall condition of the surrounding rock is good. More than 95\% of the mine's recoverable reserves are located under the Qipanjing Ecological Park, which has an industrial plaza, artificial lake, sculptures, and other buildings, as shown in Figure 1. Traditional caving mining does not meet surface deformation requirements. A suitable mining method to reduce adverse surface deformation, safely and efficiently mine the coal in this area, and extend the mine service life is therefore urgently needed.

\section{CMCB Mining Technology}

3.1. Layout of Panel Roadways. For gently inclined coal seams, the air-return roadway, haulageway, and cutting hole of the working face are excavated in advance and connected in accordance with the traditional long-wall working face layout. Air enters from the main haulageway and reaches the main air-return roadway, cutting hole, and air-return roadway. The working face forms a full negative-pressure ventilation system. To increase mining efficiency, the design length of the working face is generally about $50-100 \mathrm{~m}$. The coal seam to be mined at the working face is divided into a number of mining branches along the direction parallel to the cutting hole according to a certain width and are labeled as branches 1, 2, 3, and so on. The mode of backward backfill mining is adopted, as shown in Figure 2. The design of the branch width should consider the geological conditions of the surrounding rock and equipment size and must meet certain principles to facilitate rapid excavation, safe support, and efficient backfilling. In general, $4-6 \mathrm{~m}$ is appropriate. The main equipment used in the working face includes a fully mechanized excavator, bolter, and transfer machine, which are filled by the air-return roadway (upper roadway), and the haulageway (down roadway) is used for coal extraction.

\subsection{Mining Technology Using the CMCB Method. The backfill} mining sequence was adopted in the Yuxing mine according to the roof conditions and coal strength characteristics of the stope. After each branch roadway is mined, it is immediately backfilled and the next branch roadway is simultaneously mined in a two-step mining procedure, as shown in Figure 3. To reduce the handling of the working face equipment during the actual construction process and improve the filling and mining efficiency, it is possible to divide the continuous branches into groups and continue backfill mining in each group. After the branch is fully mined and filled, the next group is treated using the same method.

Slice mining is mostly used in branches for thick coal seams. The fully mechanized excavator mines the branch roadway from the bottom to top, starting with the upper layer. The loader transfers the coal from the branch roadway to the haulageway. An anchor trolley is used to support the roof and coal side. After the branch roadway is connected with the air-return roadway, another fully mechanized excavator is used to mine the lower layer and the former fully mechanized excavator is used to mine the upper layer of the other branch. Two fully mechanized excavators work continuously and the anchor trolley works alternately between these branches. While mining the branches, the top and bottom of the layered upper branches are filled (Figure 3). Backfilling and mining do not interfere with each other. The mode of continuous mining and continuous filling of the working face resolves the contradiction between mining and filling, allows the parallel operations to be applied to their maximum extents, and improves mining efficiency.

\section{Backfill Materials and Systems}

4.1. Backfill Materials. The backfill materials include ordinary Portland cement, fly ash from nearby power plants, washing gangue, and water. To meet the roof control 


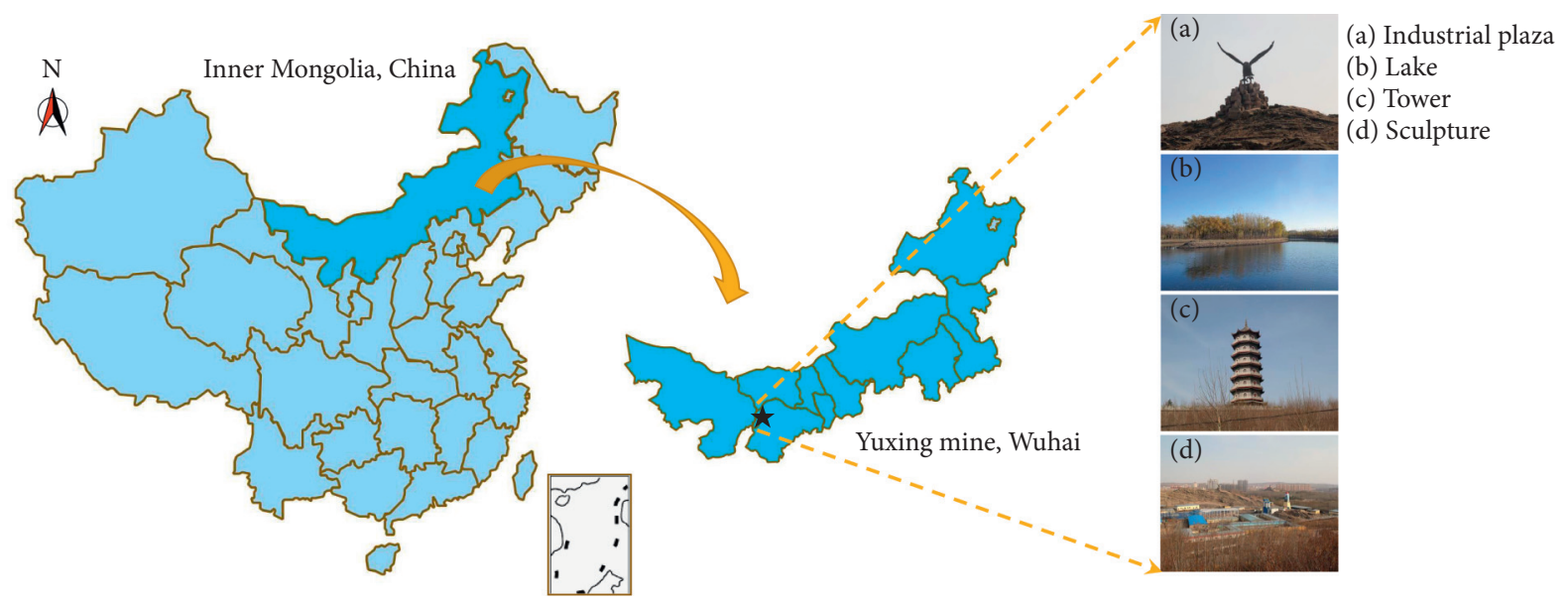

Figure 1: Overview of the Yuxing mine.

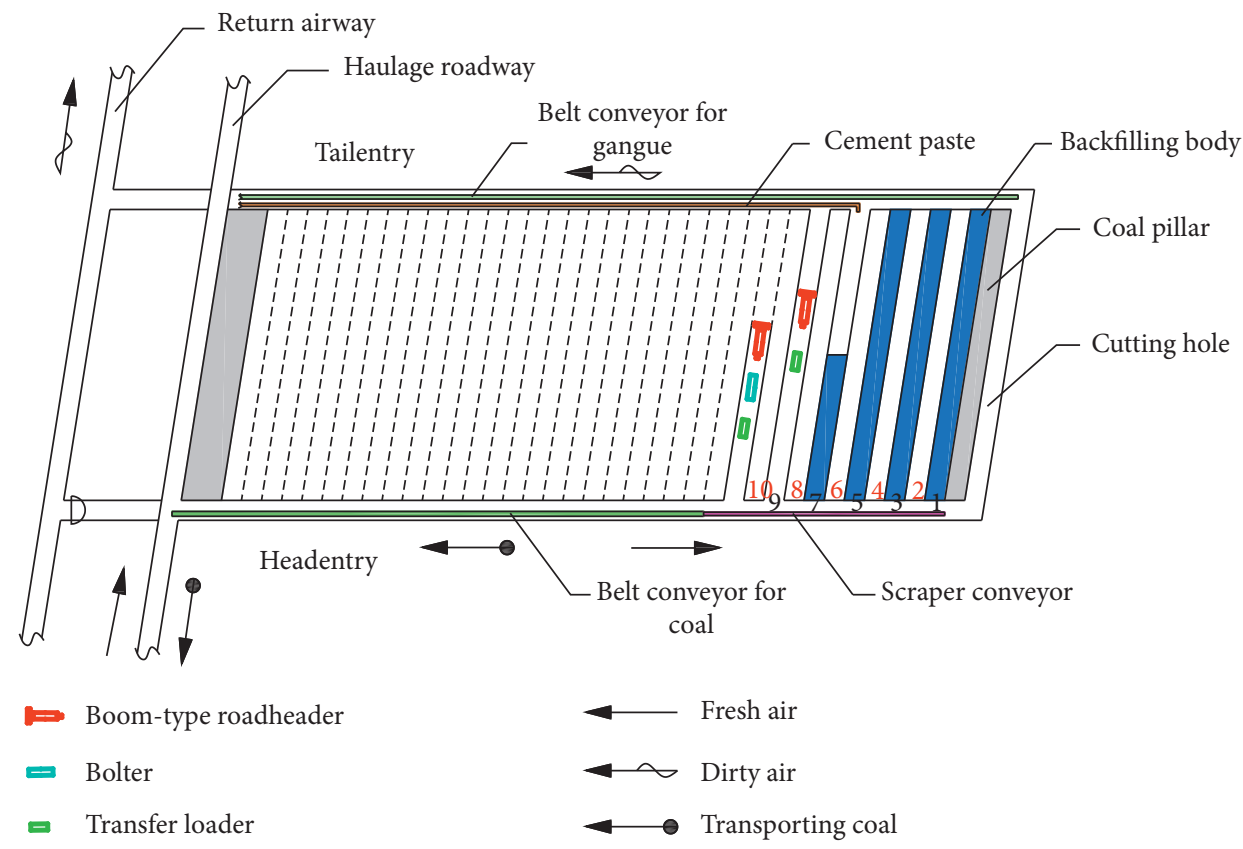

FIGURE 2: Schematic diagram of the working face layout.

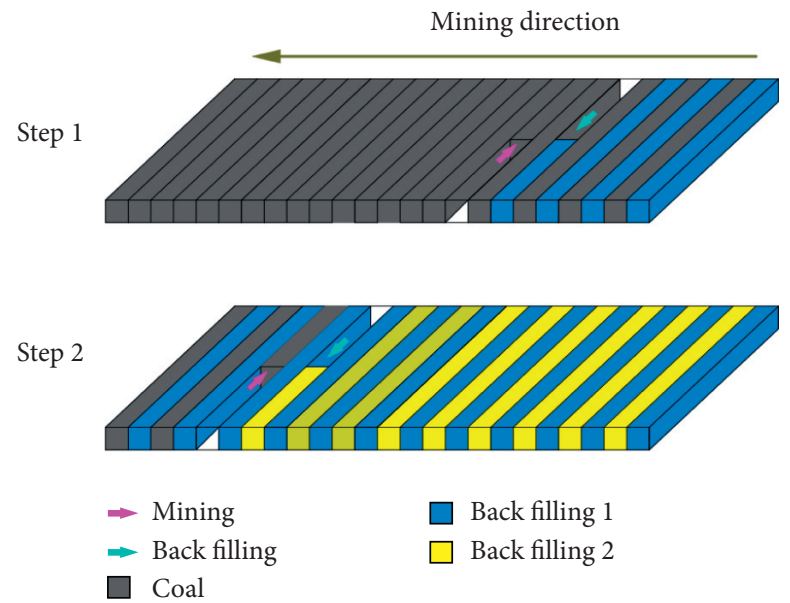

FIGURE 3: Backfill mining mode. 
requirements and facilitate the transportation of backfill materials, the preliminary backfill material design includes $10 \%$ cement, $20 \%$ fly ash, $50 \%$ gangue, and $20 \%$ water, which requires a curing time of 28 days. After curing, the material strength can reach approximately $4 \mathrm{MPa}$.

4.2. Backfill System. To reduce the probability of pipe blockage accidents during the filling-slurry transport process, two independent backfill material transportation systems are adopted: gangue in one and cement, fly ash, and water in the other. The backfill materials are mixed according to their given proportions at the working face to ensure the reliability of the transportation system.

4.2.1. Gangue Transportation System. Ground-washed gangue is delivered through a dedicated gangue feeding shaft. A gangue buffer silo is arranged at the bottom of the feeding shaft. After the gangue reaches the buffer silo, it is transported to the working surface by a conveyor belt, as shown in Figure 4.

4.2.2. Cement Slurry Transportation System. The cement, fly ash, and water are made into a cement slurry at the filling station on the ground according to the designed proportions using an automatic slurry preparation system (as shown in Figure 5). The slurry is transported underground through vertical slurry pipelines and conveyed to the working face through horizontal slurry pipelines.

4.2.3. Self-Backfilling of Mixed Slurry. The gangue conveyor belt and slurry conveyor pipeline are arranged in parallel in the air-return roadway, and the filling material is mixed at the upper opening of the branch. The conveyor speed of the filling material is controlled to ensure the suitable proportion of filling material. Before backfilling, a special plugging device is arranged at the lower opening of the branch to prevent the slurry from collapsing. After the filling slurry is mixed, the inclination of the coal and initial kinetic energy can be used to form a flow-like slurry. The filling material is evenly mixed during the self-flowing process and the filling materials are uniformly mixed via gravity filling of the branch roadway. The working face filling rate can reach more than $95 \%$, which ensures the backfilling body strength, as shown in Figure 6.

\section{Stress Evolution Characteristics of the Surrounding Rock}

The CMCB method was adopted in the \#2907 working face of the Yuxing mine. The burial depth of the coal seam was $320 \mathrm{~m}$, the roof was stable, the coal and rock mass strength were relatively high, and the width of the working face was $5 \mathrm{~m}$. The branches were divided into several groups to reduce the handling of the working face equipment and improve the filling efficiency. Every six consecutive branches formed a group and the group adopted the two-step mining mode. After the first group had finished, the second group was mined in sequence. The following groups were mined using this method to achieve full mining and backfilling of the working face. A numerical model was developed to determine the bearing capacities of the coal pillars and backfills during this process based on the working face background.

5.1. Numerical Model. To simplify the calculation, the model size was set to $240 \mathrm{~m}$ in length, $1 \mathrm{~m}$ in width, and $120 \mathrm{~m}$ in height. The section size of the simulated branch was $5.0 \mathrm{~m}$ wide and $5.0 \mathrm{~m}$ high, and 50 -meter boundary coal pillars were set on the left and right sides of the working face to eliminate boundary effects. The length of the simulated working face was $140 \mathrm{~m}$. Twenty-eight branches were set, numbered 1, 2, 3, etc., from left to right. The numerical model contained 17,652 nodes and 8560 elements. The Mohr-Coulomb model was selected as the constitutive model. Based on the strength test results of intact rock, the mechanical parameters of rock mass are reduced to a certain extent by the method of references $[33,34]$. The rock mass mechanical parameters used in the numerical model are shown in Table 1. A 5-meter coal pillar of the coal seam to be mined was regarded as a branch. A 180-meter-long survey line was arranged in the roof, floor, and coal seam of the working face, and the left and right sides both exceeded the mining boundary by $20 \mathrm{~m}$. Among them, the \#1 survey line was $1 \mathrm{~m}$ from the coal roof, the \#2 survey line was arranged in the middle of the coal seam, and the \#3 survey line was $1 \mathrm{~m}$ from coal seam floor. Measuring points were arranged every $1 \mathrm{~m}$ along the measuring line to monitor the vertical stress changes in the filling body, coal seam, and surrounding rock during the CMCB process.

5.2. Dynamic Migration Law of Stress. During advancement of the working face, a vertical stress cloud map of the surrounding rock was obtained after the completion of mining and filling and the vertical stress curve of the surrounding rock of the filling stope was drawn based on the monitoring data. The vertical stress change law of the rock surrounding the stope is similar during the two-step mining process of each group. The vertical stress variation characteristics of the surrounding rock during the backfilling and mining process of the first three groups are shown in Figures 7-9.

After completing the one-step mining of the first group, the stress of the filling bodies and coal pillars showed a $\mathrm{W}$-shaped distribution state. The stresses of the filling bodies and roof and floor of the branch were relatively small: 0.01 , 1.75 , and $0.6 \mathrm{MPa}$, respectively. The coal pillars were in the peak stress area. The peak stresses of the coal pillar, roof, and floor were 5.8, 2.5, and 3.6 $\mathrm{MPa}$, respectively. At this time, the coal pillar was the main bearing body. After completion of the two-step recovery in the first group, the vertical stress of the backfills still presented a W-shaped distribution state and the stress in the one-step backfill was greater than the two-step backfills, which indicates that the backfills after one-step mining were the main bearing body. During the mining process of the third group, the stresses in the filling bodies of the first and second groups increased and the 


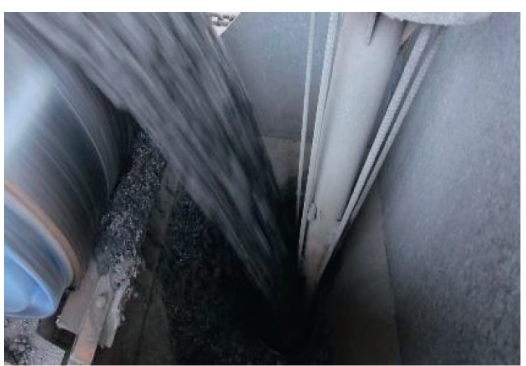

(a)

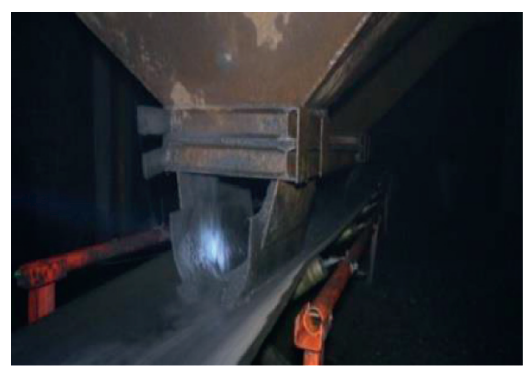

(b)

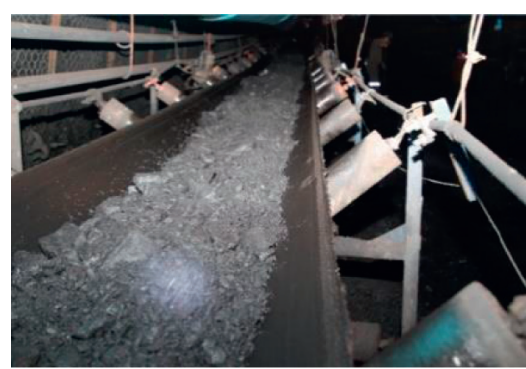

(c)

Figure 4: Gangue transportation system. (a) Gangue delivery. (b) Buffer silo. (c) Conveyor belt.

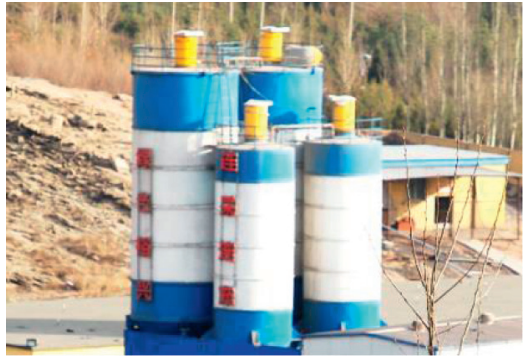

(a)

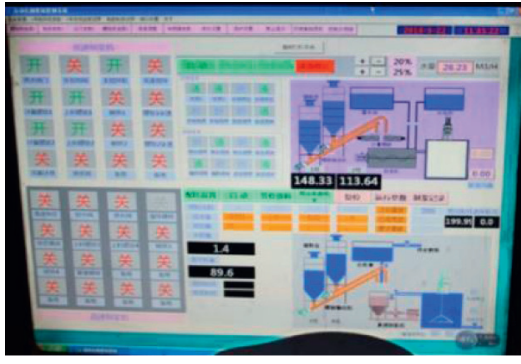

(b)

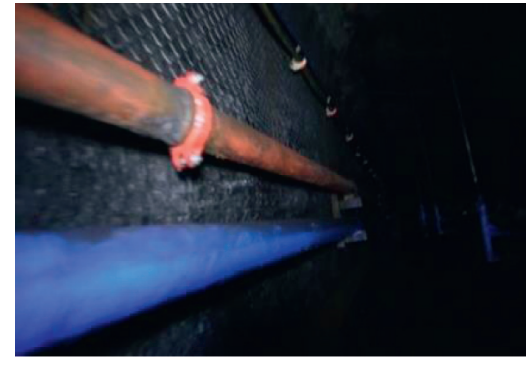

(c)

Figure 5: Cement slurry transportation system. (a) Storage bin. (b) Preparation of slurry. (c) Transportation pipeline.

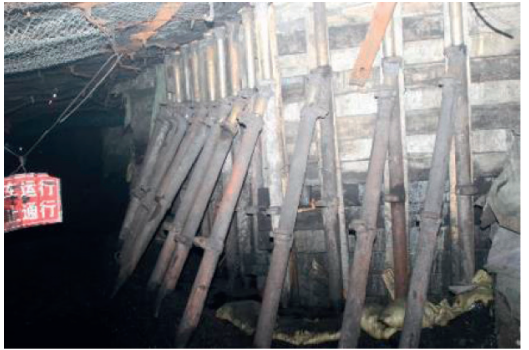

(a)

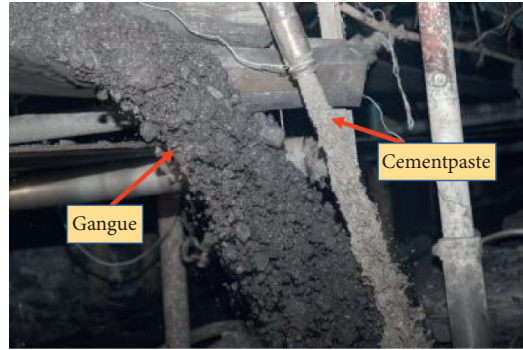

(b)

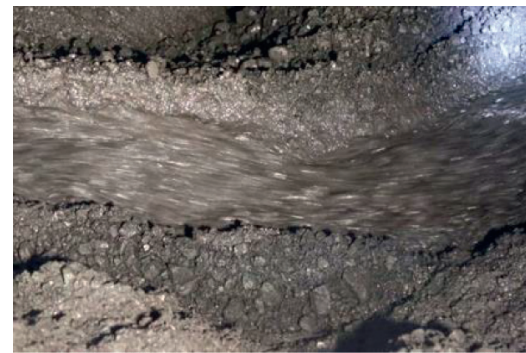

(c)

FIgURe 6: Filling slurry plugging and self-filling. (a) Plugging device. (b) Slurry mixing. (c) Self-flowing slurry.

TABLE 1: Physical and mechanical parameters of rock mass used in the numerical model.

\begin{tabular}{|c|c|c|c|c|c|c|}
\hline $\begin{array}{l}\text { Type of } \\
\text { materials }\end{array}$ & $\begin{array}{l}\text { Density } \\
\left(\mathrm{g} \cdot \mathrm{cm}^{-3}\right)\end{array}$ & Bulk modulus (GPa) & Shear modulus (GPa) & Cohesion (MPa) & Internal friction angle $\left(^{\circ}\right)$ & Tensile strength (MPa) \\
\hline $\begin{array}{l}\text { Medium } \\
\text { sandstone }\end{array}$ & 2.50 & 6.17 & 4.07 & 2.12 & 34.0 & 2.5 \\
\hline Mudstone & 2.53 & 3.02 & 1.38 & 1.22 & 27.3 & 1.2 \\
\hline Coarse sandstone & 2.42 & 6.42 & 4.25 & 2.20 & 35.0 & 2.4 \\
\hline Fine sandstone & 2.52 & 4.70 & 2.56 & 2.18 & 30.0 & 2.0 \\
\hline Coal & 1.42 & 1.94 & 0.85 & 1.05 & 26.0 & 1.0 \\
\hline Siltstone & 2.60 & 3.15 & 1.50 & 1.44 & 28.0 & 1.5 \\
\hline Filling body & 1.85 & 0.96 & 0.40 & 0.75 & 16.0 & 0.6 \\
\hline
\end{tabular}



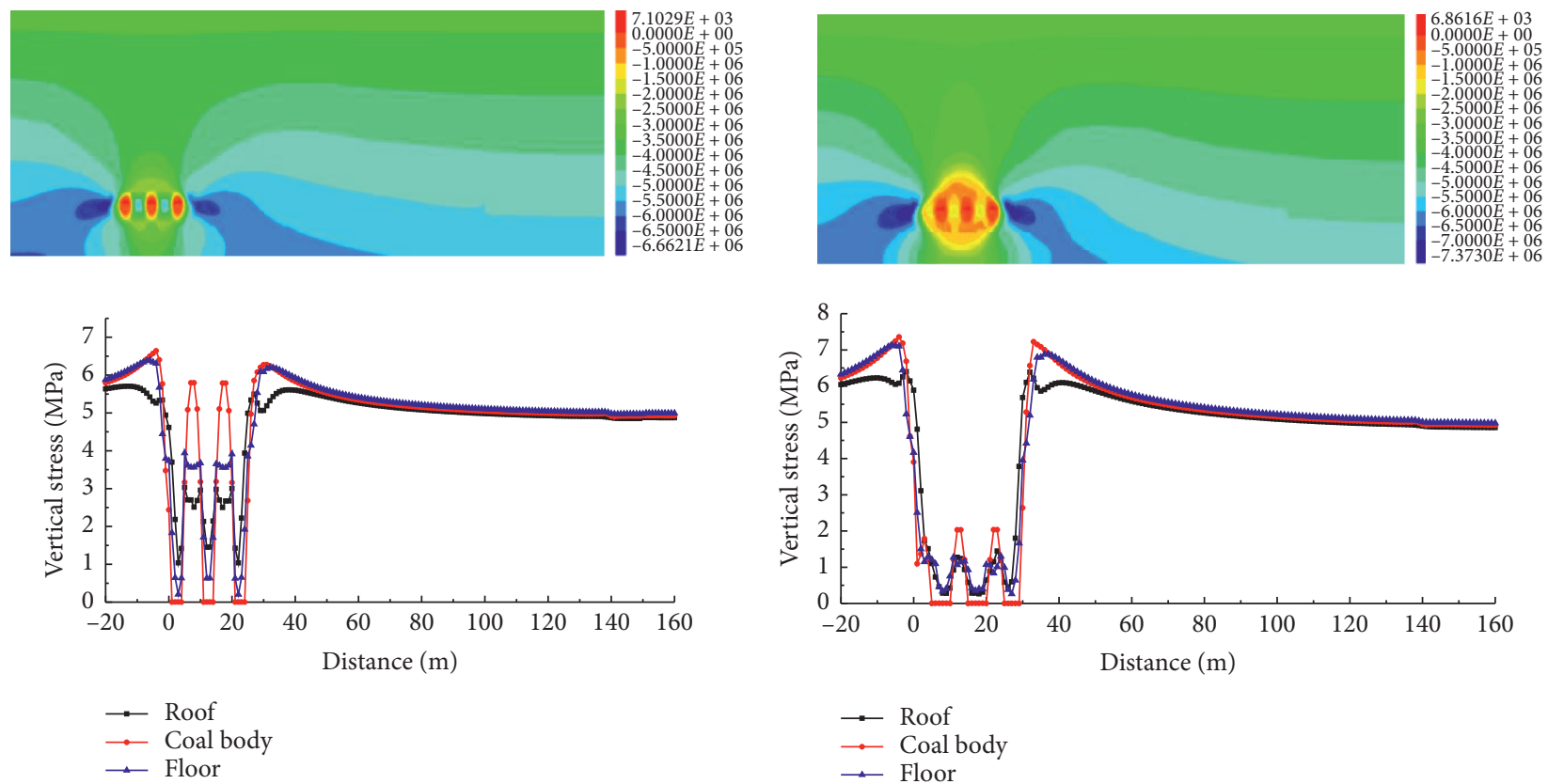

(a)

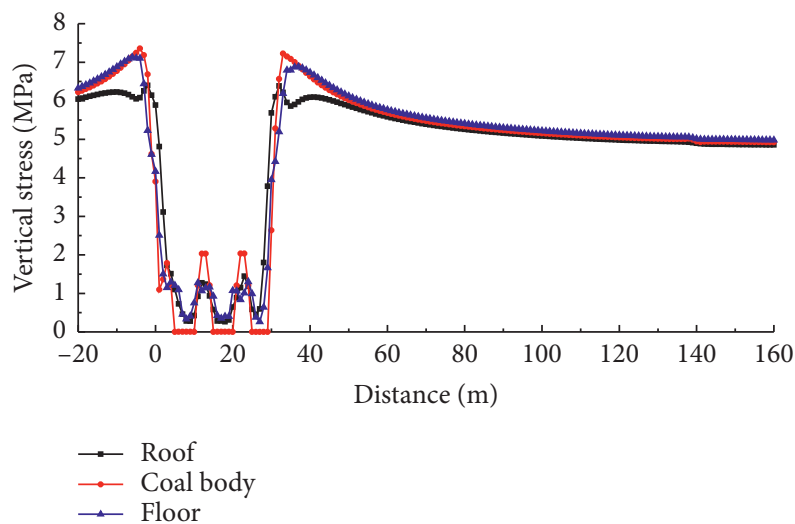

(b)

FIGURE 7: Filling and mining in the first group. (a) One-step mining stress contour and curve. (b) Two-step mining stress contour and curve.
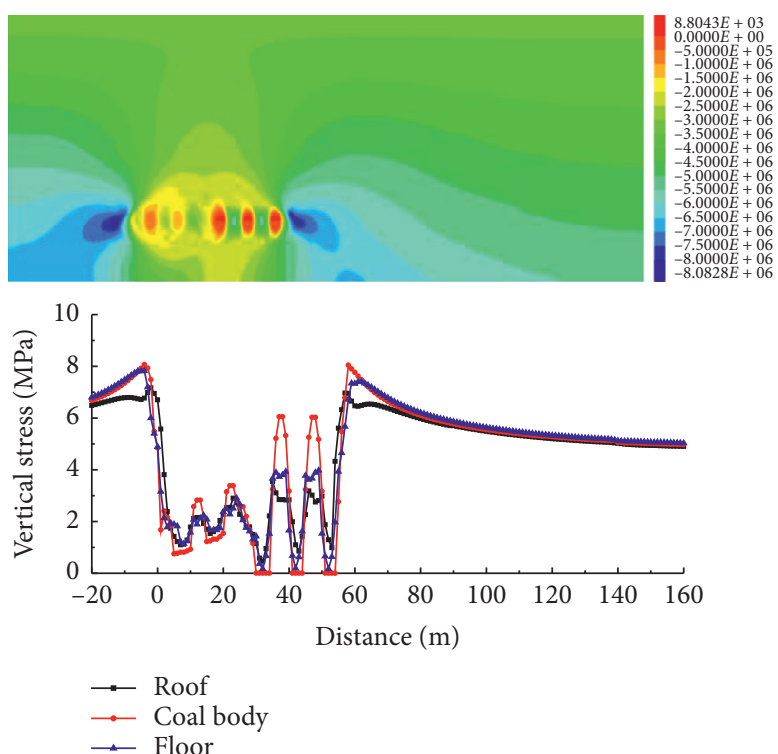

(a)
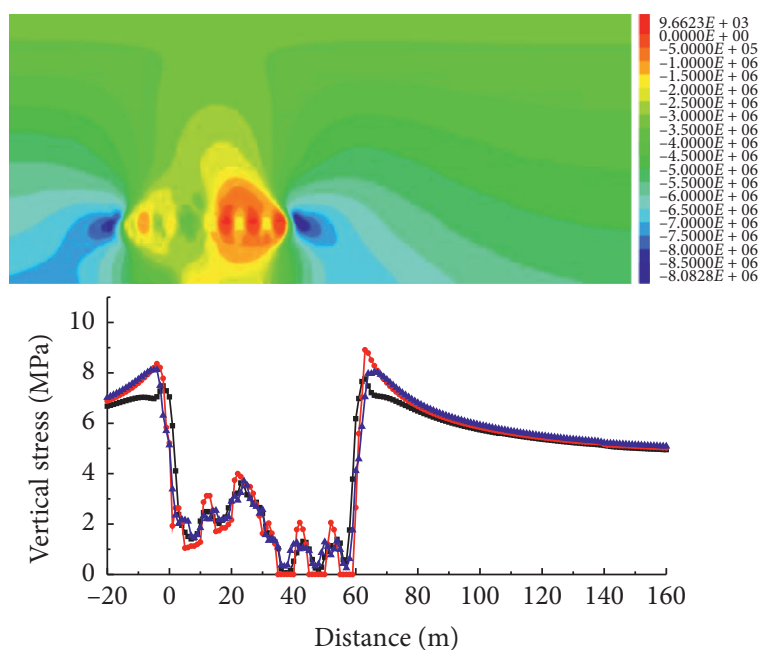

$\because$ Roof

(b)

FIGURE 8: Filling and mining in the first group. (a) One-step mining stress contour and curve. (b) Two-step mining stress contour and curve.

bearing capacity was gradually exerted. The stresses of the filling bodies and coal pillars still showed a W-shaped distribution after one-step mining in the third group. The stress of the backfill was $<0.3 \mathrm{MPa}$ and the peak stress of the coal pillar was significantly higher $(2.3 \mathrm{MPa})$. After completion of the two-step mining in the third group, the stress in the one-step backfill was greater than that of the two-step backfills, which indicates that the one-step mining filling body was the main bearing body. After the two-step mining process of the fifth group was completed, the surrounding rock stress was symmetrically distributed along the working face and the peak stress of surrounding rock was located on the coal at both sides of the working face. The difference of the filling body vertical stresses of each group in the goaf was reduced to an average of approximately $3 \mathrm{MPa}$. At this time, the filling material was the main body that supported the roof of the goaf. Overall, the two-step process of CMCB mining method alternates the bearing main body between 

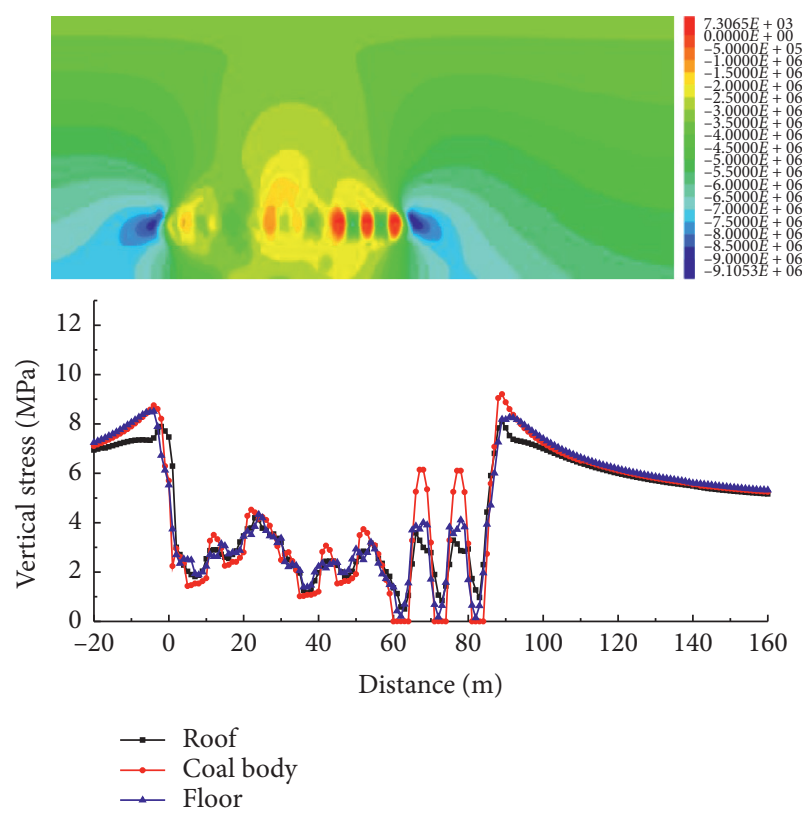

(a)
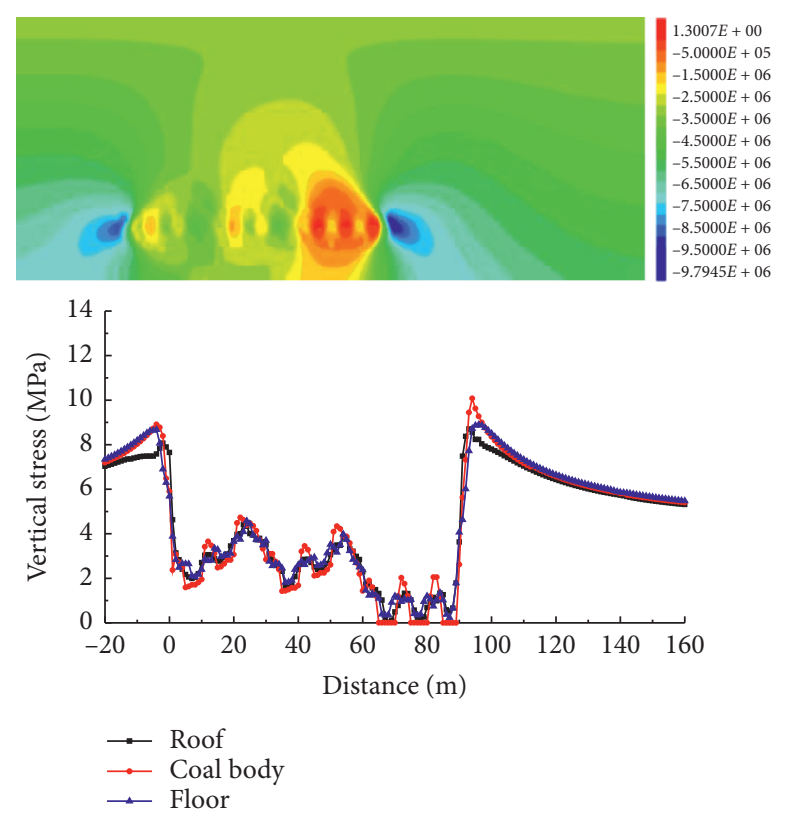

(b)

FIGURE 9: Filling and mining in the first group. (a) One-step mining stress contour and curve. (b) Two-step mining stress contour and curve.

coal pillars and filling bodies. During one-step mining, the coal pillars ensure the stability of the filling space. During the two-step mining process, this area has been solidified and filled, which stabilized the filling space. After completing the two-step mining process, the filling body began to serve as the bearing body to support the goaf roof.

\section{Movement Characteristics of Overlying Strata}

6.1. Similar Model Design. A similar simulation was performed to further analyze the movement and deformation characteristics of the overlying strata during CMCB cemented backfill mining. The size of the simulation test was $2400 \mathrm{~mm}$ in length, $200 \mathrm{~mm}$ in width, and $1300 \mathrm{~mm}$ in height. To account for the excavation scope, the geometric similarity ratio was set to $1: 100$ and the bulk density similarity ratio to $1: 1.6$. To reflect the movement characteristics of the overlying strata after filling and mining, it is necessary to ensure that the prototype and model satisfy similar motion, stress, and external forces. The simulation material was mainly composed of two components: aggregate and cement. In this experiment, the aggregate was finegrained sand and the cement was lime and gypsum. The material ratio was determined according to the physical and mechanical properties of the coal and rock layers in the backfill mining face, as listed in Table 2.

The model was designed in strict accordance with the geological structure of the rock strata. Because of some model limitations, the coal seam floor was simplified and the coal seam floor height was set to $200 \mathrm{~mm}$. During the process of laying coal and rock layers, the thickness of each layer was generally not more than $20 \mathrm{~mm}$ to ensure that the layers were flat and even. Mica powder was paved between each layer to simulate coal and rock layer bedding. The total height of this
TABle 2: Proportion of materials.

\begin{tabular}{lccc}
\hline No. & Type of materials & $\begin{array}{c}\text { Matching } \\
\text { number }\end{array}$ & Simulation material \\
\hline 1 & Medium & 855 & \\
2 & sandstone & 864 & \\
3 & Mudstone & 855 & Fine sand : lime: \\
4 & Fine sandstone & 846 & gypsum \\
5 & Coal & 973 & \\
6 & Siltstone & 864 & \\
7 & Filling body & 982 & \\
\hline
\end{tabular}

test model was $1200 \mathrm{~mm}$ to simulate the $120 \mathrm{~m}$ of the coal and rock layers. The thickness of the coal seam floor was set to $20 \mathrm{~m}$. Because the burial depth of the simulated working face was $320 \mathrm{~m}$, the remaining rock layers were loaded with counterweights on the top of the model.

6.2. Test System and Measurement Point Layout. A digital image correlation measurement system was used for data collection and analysis to improve measurement accuracy. Black cardboard was manually cut and fixed on the model using small nails to form a speckle. The speckle spacing of the coal seam and surrounding overlying rock was $10-15 \mathrm{~mm}$. The speckle spacing above the model can be appropriately increased and the spot size was approximately $100 \mathrm{~mm}^{2}$. The speckle arrangement area was $2000 \mathrm{~mm}$ in width and $1000 \mathrm{~mm}$ in height, as shown in Figure 10.

After the speckles were arranged, the counterweight was loaded on top of the model to simulate the remaining rock. After balancing the system, the initial displacement data of the overlying strata were collected. To reduce the influence of 
the model boundary on rock movement, 500-millimeter coal pillars were maintained on both sides of the model and the advancing length of the filling/mining face was $1400 \mathrm{~mm}$. The filling/mining process was simulated according to the field-grouped filling/mining mode.

6.3. Analysis of Overlying Strata Movement Characteristics during Backfill Mining. When the working face was mined to the 7th branch, a slight separation occurred at 3.5 and $5 \mathrm{~m}$ above the roof. When the backfilling mining reached the 16th branch, the separation layer behind the working face gradually closed and a slight separation layer was observed $10 \mathrm{~m}$ above the roof. When the working face advanced $140 \mathrm{~m}$ (i.e., when the 28th branch was mined), the separation layer was closed within $15 \mathrm{~m}$ of the roof in the middle of the working face. During the backfilling and mining process, the roof layers underwent the process of stabilization, separation, expansion, and closure. There was no structural damage to the overlying rock roof after the working face was filled with mining. Compared with traditional caving mining, there was no caving or crack zone, only a curved sinking zone. The roof rock beam maintained its integrity and continuity and the stope roof slowly bent and sank, as shown in Figure 11.

Digital image correlation was used to quantitatively analyze the roof deformation at different overburden positions and determine the evolution process of the vertical displacement field of the overburden during advancement of the working face, as shown in Figure 12.

During mining, the overburden roof load gradually shifted from the coal pillar to the backfills. During the conversion of the support body, the roof displacement of the coal pillar was less than that of the backfills. Upon increasing the advancing distance, the disturbance range of the roof increased and the load-bearing effect of the goaf filling body gradually increased. The structural breakage of the roof was thereby restricted and mainly appeared as bending and sinking. To compare and analyze the roof displacement changes at different overburden positions during the filling and mining process, eight horizontal survey lines were arranged at positions 5,10 , $15, \ldots, 40 \mathrm{~m}$ from the coal roof. The amount of roof subsidence at different overlying rock positions is shown in Figure 13, when the working face had reached $70 \mathrm{~m}$ (i.e., filled to the 14th branch) and $140 \mathrm{~m}$ (i.e., filled to the $28 \mathrm{th}$ branch). When the working face had reached $70 \mathrm{~m}$, the maximum roof subsidence at $5 \mathrm{~m}$ of overlying strata was approximately $350 \mathrm{~mm}$ with little difference in roof subsidence above $30 \mathrm{~m}$. The maximum roof displacement was $30 \mathrm{~m}$ from the initial mining line, which lagged behind the middle of the goaf. When the working face reached $140 \mathrm{~m}$, the maximum roof subsidence at $5 \mathrm{~m}$ was $550 \mathrm{~mm}$, the difference in roof subsidence above $30 \mathrm{~m}$ was small, and the maximum displacement of the roof was $40 \mathrm{~m}$ from the mining line. These results show that after the coal seam was replaced by the backfill and the loadbearing effect of the backfill was gradually notable with increasing mining distance.

\section{Practical Application}

The CMCB mining technology proposed here was applied in the no. 9 coal seam of the Yuxing mine. According to the engineering geological conditions of the coal seam, the designed dimensions of each branch roadway were set to $5 \mathrm{~m}$ in width, $5 \mathrm{~m}$ in height, and $60 \mathrm{~m}$ in length. The length of the working face was approximately $400 \mathrm{~m}$. The support roadway adopted two fully mechanized excavators for mining. The roadway roof was supported by bolts and cables using MSGLD-335/18 bolts with a length of $2000 \mathrm{~mm}$, and the anchoring length was not less than $700 \mathrm{~mm}$. Four anchors were arranged in each row at a distance between adjacent anchors and rows of 1300 and $1500 \mathrm{~mm}$, respectively. An anchor cable was arranged in the center of the roof every $3000 \mathrm{~mm}$. The anchor cable was composed of seven steel strands with a diameter of $17.8 \mathrm{~mm}$, length of $5200 \mathrm{~mm}$, and an anchorage length of not less than $1500 \mathrm{~mm}$. Bolts were adopted when the two sides of the branch were coal seams. Two bolts were arranged in each row at a distance between adjacent anchors and rows of 1200 and $1500 \mathrm{~mm}$, respectively. The upper anchor was $300 \mathrm{~mm}$ from the roof. The procedure was generally not supported if the two sides of the branch were filled with backfill materials.

The state of the filling bodies during different filling stages is shown in Figure 14. The filling body shows high integrity with no appearance of significant cracks and can secure the roof and ensure coal safety between the two filling bodies. Eight working faces of the no. 9 coal seam have so far been mined with a coal resource recovery rate from the working faces of $>95 \%$. The internal structure of the roof is shown in Figure 15. The results of the internal roof structure do not show a caving zone or crack zone and roof deformation is dominated by delamination, which is consistent with the simulation results. Delamination is more developed in the 2.5-meter range of the roof. The separation layer is distributed between 2.5 and $9.0 \mathrm{~m}$ and the overall roof stability is good. Surface deformation was monitored during the filling and mining process. The maximum surface subsidence was $30 \mathrm{~mm}$, the maximum horizontal movement was $12 \mathrm{~mm}$, the maximum horizontal deformation was $0.7 \mathrm{~mm} / \mathrm{m}$, the maximum curvature was $0.05 \mathrm{~mm} / \mathrm{m}^{2}$, and the maximum tilt was $0.4 \mathrm{~mm} / \mathrm{m}$. The surface deformation was within the I-level range, which meets the national standard requirements and can achieve the safe and efficient replacement of coal resources in this location.

\section{Discussion}

The characteristics of CMCB cemented-fill mining technology in gently inclined coal seams can be summarized as a long-wall layout, short-wall mining, interval coal mining, and stepwise filling. The working face does not use hydraulic supports or filling pressure pumps, which greatly reduces the initial investment and mining cost. The use of cemented-fill mining effectively controls ground surface deformation. The gangue and cement slurry in the filling material are two independent conveying systems. The filling material is changed from ground mixing to working-face mixing, which 


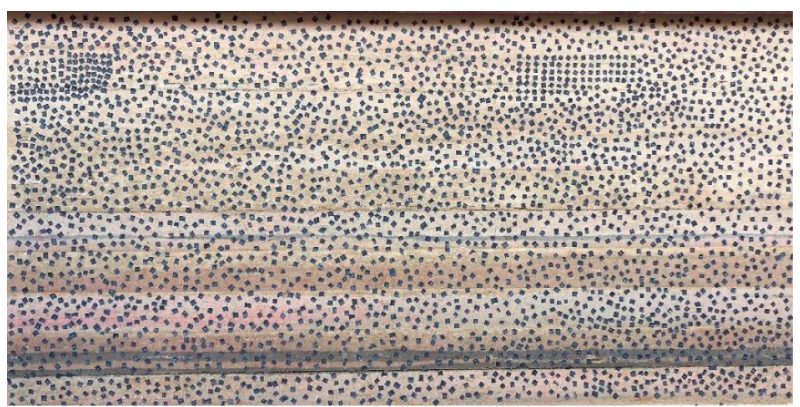

FIGURE 10: Speckle layout.

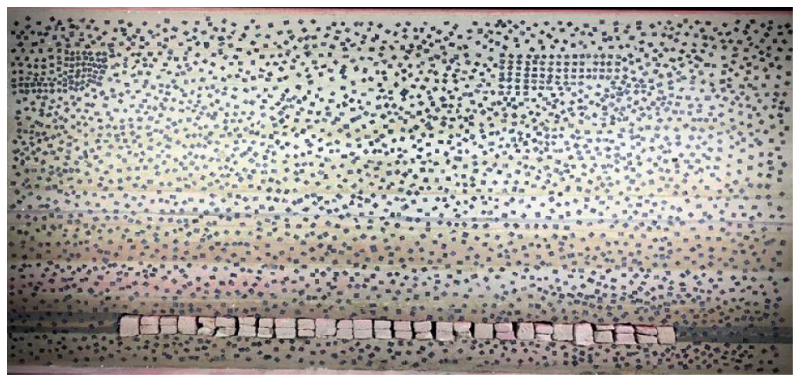

FIGURE 11: Movement characteristics of overburden strata at an advance of $140 \mathrm{~m}$ in the filling face.

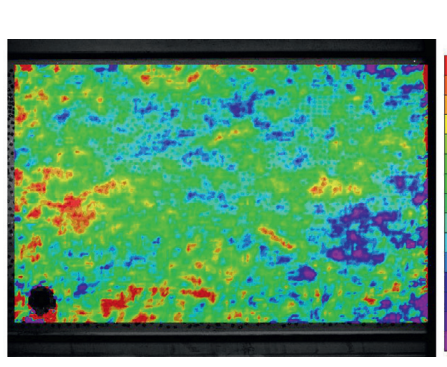

(a)

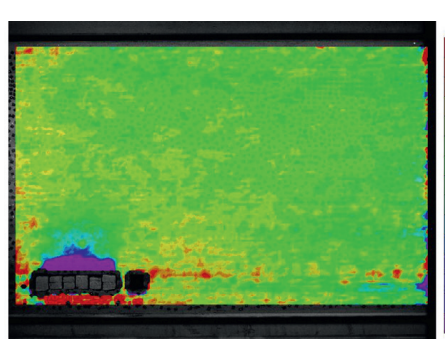

(d)

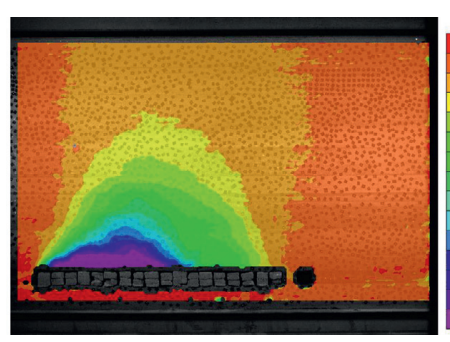

(g)

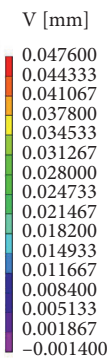

$\mathrm{V}[\mathrm{mm}]$

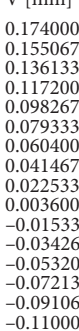

$-0.091067$

$\mathrm{V}[\mathrm{mm}]$

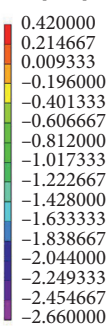

-2.454667
-2.660000

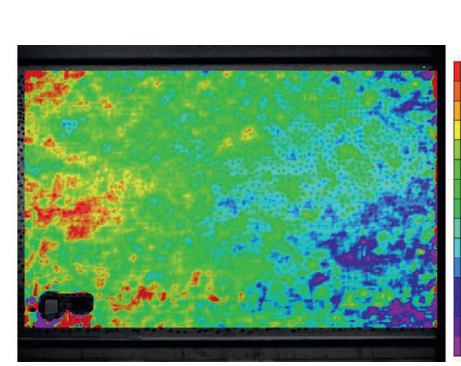

$\mathrm{V}[\mathrm{mm}]$
0.057000
0.052333
0.047677
0.043000
0.038333
0.033667
0.029000
0.024333
0.019667
0.015000
0.010333
0.005667
0.001000
-0.003667
-0.008333
-0.013000

(b)

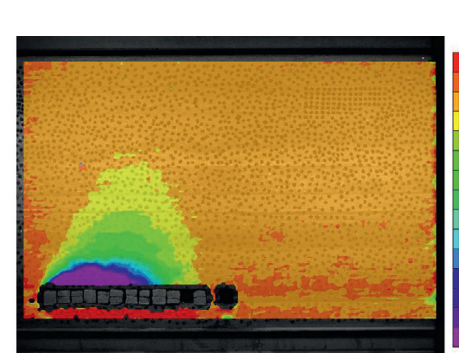

(e)

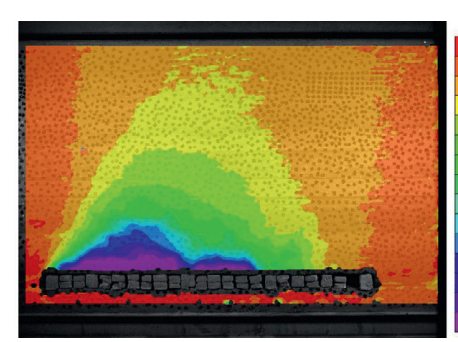

(h)

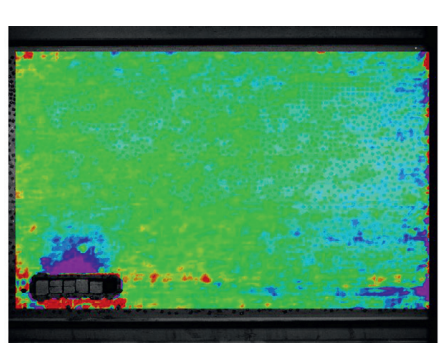

$\mathrm{V}[\mathrm{mm}]$

0.155000 0.144200
0.133400
0.12180 0.122600
0.111800
0.1000 0.101000 0.090200 0.079400 0.068600 0.047000 0.036200 0.036200
0.025400
0.014600 0.025400
0.014600
0.003800

(c)

$\mathrm{V}[\mathrm{mm}]$
0.350000
0.242667
0.135333
0.028000
-0.079333
-0.186667
-0.294000
-0.401333
-0.508667
-0.616000
-0.723333
-0.830667
-0.938000
-1.045333
-1.152667
-1.260000

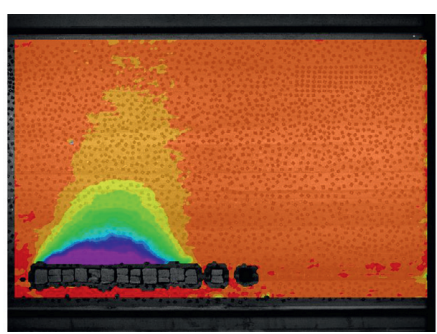

$\mathrm{V}[\mathrm{mm}]$

0.360000 0.184000
0.008000 0.08000
-0.168000
-0.344000 -0.344000
-0.520000
-.05600 -0.520000
-0.696000 $-0.872000$ $-1.048000$ -1.224000
-1.400000 $-1.576000$ -1.576000
-1.752000
-1.928000
-2.28000 -1.928000
-2.104000
-2.28000

(f) $\mathrm{V}[\mathrm{mm}]$
0.460000
0.224000
-0.012000
-0.248000
-0.484000
-0.720000
-0.956000
-1.192000
-1.428000
-1.664000
-1.900000
-2.136000
-2.372000
-2.608000
-2.844000
-3.080000

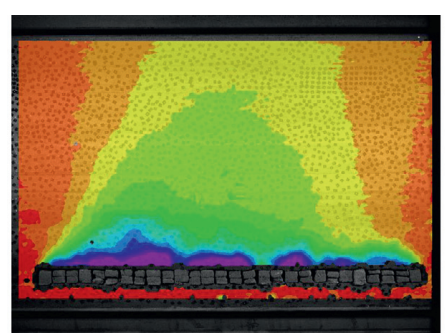

$\mathrm{V}[\mathrm{mm}]$ 0.480000 0.158667
-0.16266 -0.162667
-0.484000
-0.805333 -0.484000
-0.805333
-1.126667 -1.448000
-1.769333 $-2.090667$ -2.412000
-2.733333 -2.733333
-3.054667 -3.054667
-3.376000 -3.376000
-3.697333 -3.697333
-4.018667
-4.340000

(i)

FIgURE 12: Evolution of the vertical displacement field of the overlying strata during the filling and mining process. (a) $5 \mathrm{~m}$. (b) $15 \mathrm{~m}$. (c) $30 \mathrm{~m}$. (d) $40 \mathrm{~m}$. (e) $60 \mathrm{~m}$. (f) $80 \mathrm{~m}$. (g) $100 \mathrm{~m}$. (h) $120 \mathrm{~m}$. (i) $140 \mathrm{~m}$. 


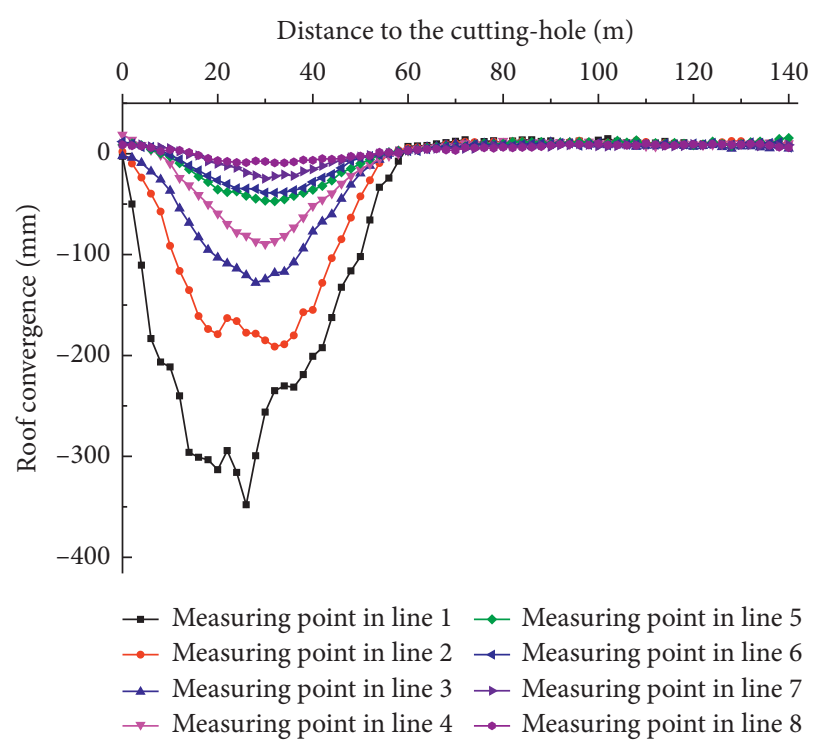

(a)

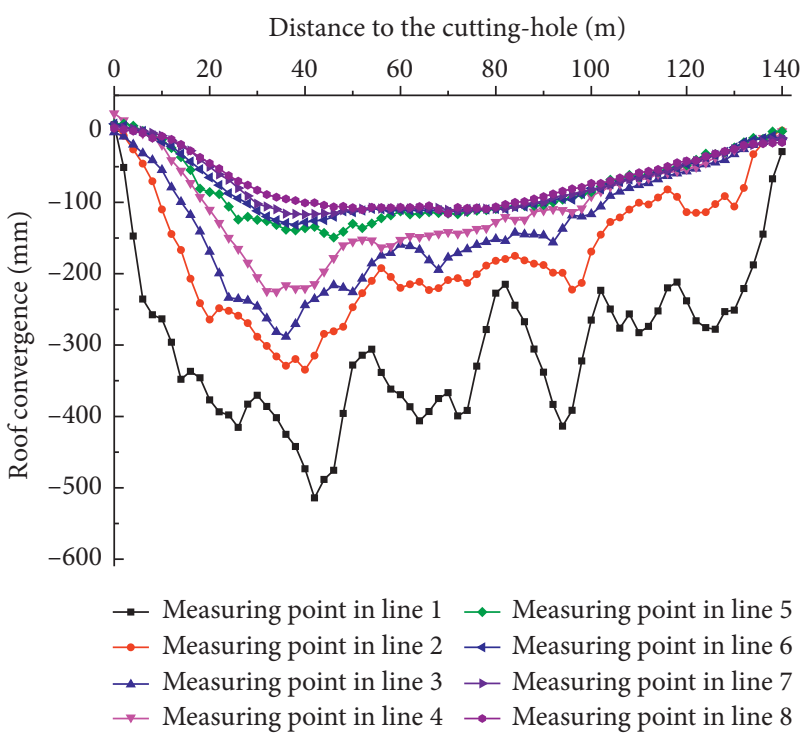

(b)

FIGURE 13: Roof subsidence at different overlying rock positions. (a) $70 \mathrm{~m}$. (b) $140 \mathrm{~m}$.

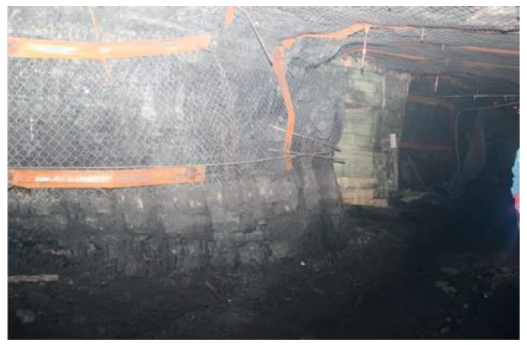

(a)

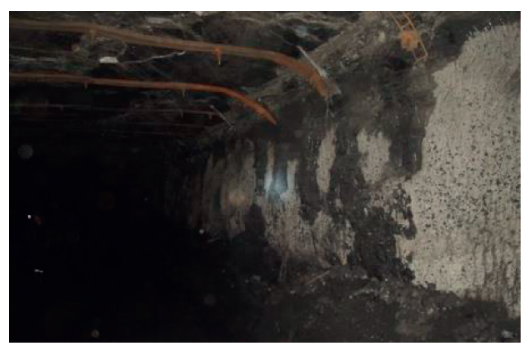

(b)

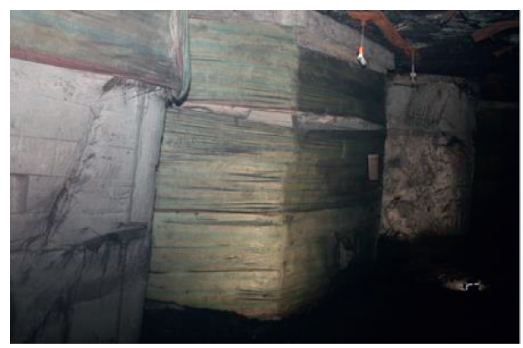

(c)

FIGURE 14: Exposure of the filling body at different backfill mining stages. (a) One-step mining. (b) Two-step mining. (c) Full mining and full backfilling.

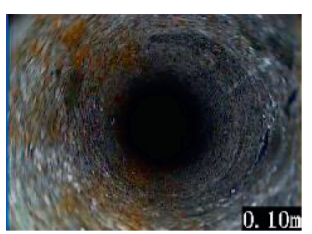

(a)

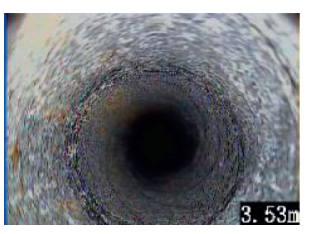

(f)

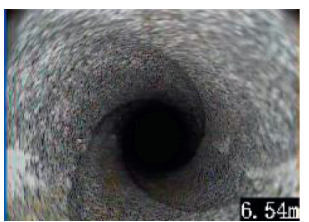

(k)

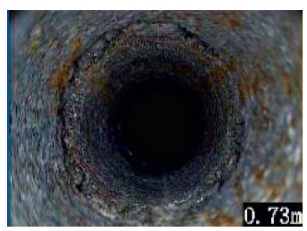

(b)

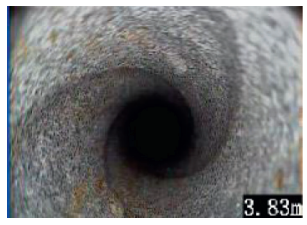

(g)

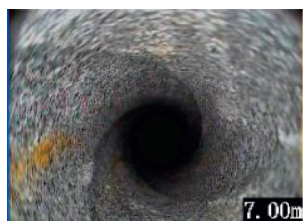

(l)

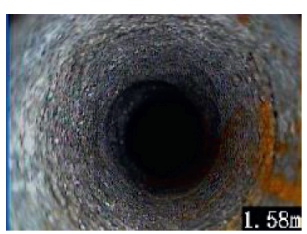

(c)

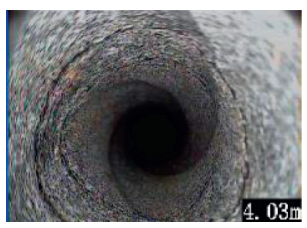

(h)

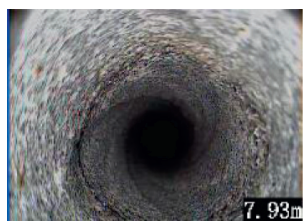

(m)

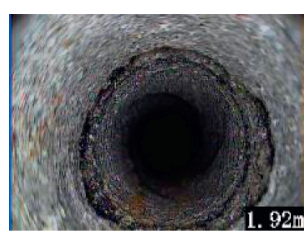

(d)

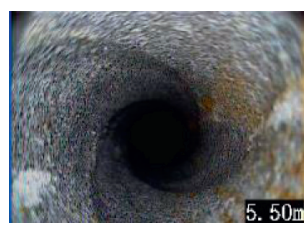

(i)

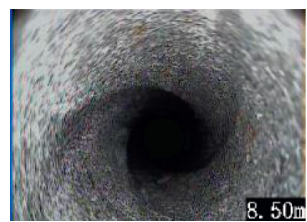

(n)

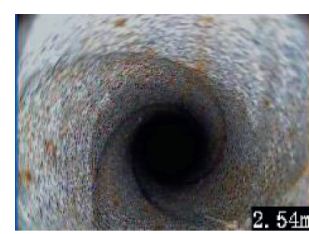

(e)

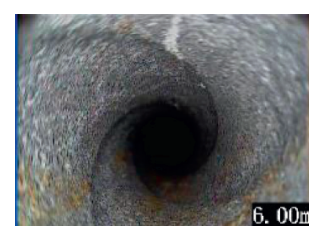

(j)

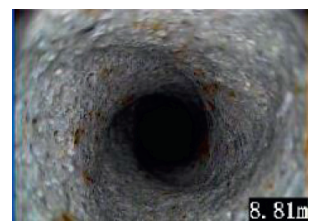

(o)

Figure 15: Internal roof structure after backfilling. (a) $0.10 \mathrm{~m}$. (b) $0.73 \mathrm{~m}$. (c) $1.58 \mathrm{~m}$. (d) $1.92 \mathrm{~m}$. (e) $2.54 \mathrm{~m}$. (f) $3.53 \mathrm{~m}$. (g) $3.83 \mathrm{~m}$. (h) $4.03 \mathrm{~m}$. (i) $5.50 \mathrm{~m}$. (j) $6.00 \mathrm{~m}$. (k) $6.54 \mathrm{~m}$. (l) $7.00 \mathrm{~m}$. (m) $7.93 \mathrm{~m}$. (n) $8.50 \mathrm{~m}$. (o) $8.81 \mathrm{~m}$. 
reduces pipe blockage accidents during the transportation process. Uniform mixing of the filling material is achieved through gravity flow, which can ensure filling body strength. The working face adopts a two-step mining mode. The coal pillar and solidified filling body are used as the main bodies to support the rock surrounding the roof during the one-step and two-step mining processes, respectively. The alternate bearing of the coal pillar and filling body ensures the stability of the filling space and solidification time of the filling material. Mining and filling do not interfere with each other. The working face can be continuously mined and filled with these processes operating in parallel to their respective maximum extents.

Because of the small excavation area of the branch and timely filling, the filling body maintains the integrity and bearing capacity of the surrounding rock and increases the ability of the roof to resist deformation. A support system from the joint action of the coal seam, overlying strata, and filling body forms as the working face advances. Owing to the limited movement space of the overlying strata, the surrounding rock changes the stress state of the entire working face, which significantly weakens the appearance of rock pressure. Only a curved sinking zone occurs in the overburden rock. This multicycle, small-disturbance, step-by-step replacement backfill mining mode shows significant advantages, especially for mining coal seams with stable roofs and abandoned coal resources in irregular areas. For coal seams with unstable roofs, it is necessary to further optimize the branch support to reduce the impact of supporting technology on coal production. Owing to the short service time of the branches, differentiated support methods can be used in branches. The economic and effective principles must be met to avoid the two extremes of the support plan. One is excess support, which affects the mining speed and causes material waste; the other is insufficient support, which causes roof collapse and rib spalling.

\section{Conclusions}

(1) $\mathrm{CMCB}$ mining technology is proposed to resolve the problems of large initial equipment investment and low backfill mining efficiency in traditional long-wall cemented coal mining. A complete filling material delivery system was constructed for the mining of gently inclined coal seams.

(2) During the CMCB mining process, the coal pillar and filling body alternately support each other, which ensures the stability of the filling space and curing time of the filling body and can achieve maximum parallel operations of both mining and filling, which improves backfill mining efficiency.

(3) The features of the CMCB cemented-fill mining method include a long-wall layout, short-wall mining, interval coal extraction, and step-by-step filling. This multicycle, small-disturbance backfill, and mining mode has achieved good engineering application effects. The approach significantly reduces surface deformation and can safely and efficiently replace coal resources that are difficult to mine.

\section{Data Availability}

The experimental data used to support the findings of this study are included within the article.

\section{Conflicts of Interest}

The authors declare that they have no conflicts of interest regarding the publication of this paper.

\section{Acknowledgments}

The help of the Yuxing mine is gratefully acknowledged. The authors sincerely appreciate the financial support from the National Natural Science Foundation of China (No. 51804310) and the Fundamental Research Funds for the Central Universities (No. 2020XJNY05).

\section{References}

[1] S. M. Wang, "Thoughts about the main energy status of coal and green mining in China," Journal of China Coal Society, vol. 46, no. 2, pp. 11-16, 2020.

[2] S. M. Wang, Z. H. Duan, L. Ma, and Y. P. Zhang, "Research status and future trends of geological assurance technology for coal green development in Western China," Coal Science and Technology, vol. 47, no. 2, pp. 1-6, 2019.

[3] S. P. Peng and Y. L. Bi, "Strategic consideration and core technology about environmental ecological restoration in coal mine areas in the Yellow River basin of China," Journal of China Coal Society, vol. 45, no. 4, pp. 1211-1221, 2020.

[4] L. M. Fan, X. T. Zhang, M. X. Xiang, H. Q. Zhang, T. Shen, and P. X. Lin, "Characteristics of ground fissure development in high intensity mining area of shallow seam in Yushenfu coal field," Journal of China Coal Society, vol. 40, pp. 14421447, 2015.

[5] L. M. Fan, "Scientific connotation of water-preserved mining," Journal of China Coal Society, vol. 42, pp. 27-35, 2017.

[6] L. M. Fan, X. D. Ma, H. Jiang, and S. Cheng, "Risk evaluation on water and sand inrush in ecologically fragile coal mine," Journal of China Coal Society, vol. 41, pp. 531-536, 2016.

[7] G. P. Zhao, Y. L. Bi, J. B. Li, R. Gao, and C. Gao, "Effects of coal mining subsidence on wind erosion characteristics in aeolian desert region of shenfu coal mining," Bulletin of Soil and Water Conservation, vol. 36, pp. 129-132, 2016.

[8] Y. L. Bi, H. Zou, C. Peng, and L. M. Shi, "Effects of mining subsidence on soil water movement in sandy area," Journal of China Coal Society, vol. 39, pp. 490-496, 2014.

[9] J. X. Zhang, Y. Ju, Q. Zhang et al., "Low ecological environment damage technology and method in coal mines," Journal of Mining and Strata Control Engineering, vol. 1, pp. 56-68, 2019.

[10] L. M. Fan, "Some scientific issues in water-preserved coal mining," Journal of China Coal Society, vol. 44, pp. 667-674, 2019.

[11] X. X. Miao, F. Ju, Y. L. Huang, and G. L. Guo, "New development and prospect of backfilling mining theory and technology," Journal of China University of Mining \& Technology, vol. 44, pp. 391-399, 2015. 
[12] J. G. Liu, X. W. Li, and T. He, "Application status and prospect of backfill mining in Chinese coal mines," Journal of China Coal Society, vol. 45, pp. 141-150, 2020.

[13] J. G. Liu, "Application and study on backfill mining technology and equipment in deep mine with depth over $1000 \mathrm{~m}$," Coal Science and Technology, vol. 41, no. 9, pp. 58-61, 2013.

[14] G. R. Feng, X. J. Du, Y. X. Guo et al., "Basic theory of constructional backfill mining and the underground space utilization concept," Journal of Rock Mechanics and Geotechnical Engineering, vol. 44, no. 1, pp. 74-84, 2016.

[15] J. X. Zhang, Y. J. Zhou, and Y. L. Huang, "Integrated technology of fully mechanized solid backfill mining," Journal of China Coal Society, vol. 40, no. 11, pp. 10-13, 2019.

[16] M. Li, J.-x. Zhang, P. Huang, and R. Gao, "Mass ratio design based on compaction properties of backfill materials," Journal of Central South University, Journal of Central South University, vol. 23, no. 10, pp. 2669-2675, 2016.

[17] M. Li, J. X. Zhang, X. X. Miao, and Y. L. Huang, "Strata movement under compaction of solid backfill body," Journal of China University of Mining \& Technology, vol. 43, no. 6, pp. 969-973, 2014.

[18] J. Zhang, M. Li, Z. Liu, and N. Zhou, "Fractal characteristics of crushed particles of coal gangue under compaction," Powder Technology, vol. 305, pp. 12-18, 2017.

[19] Q. Zhang, J. X. Zhang, F. Ju, M. Li, and D. K. Geng, "Backfill body's compression ratio design and control theory research in solid backfill coal mining," Journal of China Coal Society, vol. 39, no. 1, pp. 64-71, 2014.

[20] J. X. Zhang, J. Li, T. L. An, and Y. L. Huang, "Deformation characteristic of key stratum overburden by raw waste backfilling with fully-mechanized coal mining technology," Journal of China Coal Society, vol. 35, no. 3, pp. 357-362, 2010.

[21] H. Q. Zhou, C. J. Hou, X. K. Sun, Q. D. Qu, and D. J. Chen, "Solid waste paste filling for none-village-relocation coal mining," Journal of China University of Mining \& Technology, vol. 33, no. 2, pp. 30-34, 2004.

[22] C. Z. Zhao, H. Q. Zhou, Q. D. Qu, and M. L. Guan, "Preliminary test on mechanical properties of paste filling material," Journal of China University of Mining \& Technology, vol. 33, no. 2, pp. 35-37, 2004.

[23] B. C. Zhao, D. Zhai, X. Yang, H. Sun, K. Zhao, and L. Q. Li, "Experimental study on proportion optimization of loess paste filling materials," Mining Research and Development, vol. 40, no. 3, pp. 50-55, 2020.

[24] L. Q. Ma, D. S. Zhang, S. K. Wang, Y. S. Xie, and Y. H. Yu, "Water-preserved mining with the method named "backfilling while mining," Journal of China Coal Society, vol. 43, no. 1, pp. 62-69, 2018.

[25] S. K. Wang and L. Q. Ma, "Characteristics and control of mining induced fractures above longwall mines using backfilling," Energies, vol. 12, no. 23, p. 4604, 2019.

[26] C. D. Sun, F. X. Jiang, Y. Liu, and Y. Y. Li, "Fractured zone of surrounding rock masses monitored by microseismic monitoring techniques in open backfilled mine using ultra highwater material," Chinese Journal of Rock Mechanics and Engineering, vol. 33, no. 3, pp. 475-483, 2014.

[27] C. D. Sun, D. S. Zhang, X. F. Wang, and R. Zhou, "Large-size test on creep characteristics of high water material for filling body beside roadway," Chinese Journal of Rock Mechanics and Engineering, vol. 29, no. 4, pp. 487-491, 2012.

[28] G. M. Feng, Y. Ding, H. J. Zhu, and J. B. Bai, "Experimental research on a superhigh-water packing material for mining and its micromorphology," Journal of China University of Mining \& Technology, vol. 39, no. 6, pp. 813-819, 2010.
[29] G. M. Feng, K. J. Jia, and B. B. Shang, “Application and prospect of super-high-water packing material in mining engineering," Coal Science and Technology, vol. 43, no. 1, pp. 5-9, 2015.

[30] G. M. Feng, K. J. Jia, F. K. Li, S. M. Yin, and H. H. Wang, "Research on overburden strata control using a super high water content material during open back fill mining," Journal of China University of Mining \& Technology, vol. 40, no. 6, pp. 841-845, 2011.

[31] B. G. Yang, J. T. Wang, Y. L. Li, W. C. Li, and Z. Li, “Backfill coal mining technology with high concentrated cementing material in underground mine," Coal Science and Technology, vol. 41, no. 8, pp. 22-26, 2013.

[32] B. G. Yang, J. Yang, Y. Yu, D. Li, B. Jiang, and K. Cheng, "Study on proportioning test of a new cementing filling material and hydration mechanism," Journal of Mining Science and Technology, vol. 2, no. 5, pp. 475-481, 2017.

[33] E. Hoek and E. T. Brown, "The Hoek-Brown failure criterion and GSI - 2018 edition," Journal of Rock Mechanics and Geotechnical Engineering, vol. 11, no. 3, pp. 445-463, 2019.

[34] G.-C. Zhang, F.-L. He, H.-G. Jia, and Y.-H. Lai, "Analysis of gateroad stability in relation to yield pillar size: a case study," Rock Mechanics and Rock Engineering, vol. 50, no. 5, pp. 1263-1278, 2017. 